\title{
Marsirimpa as Core Cultural Value to Improve Social Value in Siponjot Village
}

\author{
Jhonson Pardosi ${ }^{1 *}$, Joe Anto Ginting ${ }^{1}$, Afrina Veronica ${ }^{1}$, Hotlan Siahaan ${ }^{1}$ \\ ${ }^{1}$ Faculty of Cultural Study, Universitas Sumatera Utara \\ *Email: jhonson@usu.ac.id
}

\begin{abstract}
Marsirimpa as a cultural, one of the traditional cultural, values have been diminished from society by various daily activities that emphasize individual problems and individual solution. This condition does not only occur in urban areas, but also in rural areas which commonly hold a stronger value. In fact, Marsirimpa is a culture that important to overcome many obstacle in society life. The main aim of this community service is to empower the people within Siponjot Village. To be more specific, we aimed to empower Marsirimpa to foster social life within Siponjot Village. We had been held a form of Socialization has with the people of Siponjot Village, related to the transfer knowledge one of the socio-cultural values that actually they already have (in the context of the Toba Batak community), namely the concept of marsirimpa, which can be used as motivation for cooperation or mutual cooperation, and explaining natural and environmental wealth as well as creative human resources owned by Siponjot village. As result, we reached a satsifiying result that the people is more enthusiasm and changes in social values that support marsirimpa in everyday life.
\end{abstract}

Keyword: Organizational Management, Social Value, Marsirimpa

\begin{abstract}
Abstrak
Nilai-nilai budaya Marsirimpa sebagai salah satu nilai budaya tradisional mulai tergeser dengan berbagai aktivitas keseharian yang lebih menekankan pada penyelesaian permasalahan individu. Kondisi ini tidak hanya terjadi di wilayah perkotaan saja, tetapi juga di wilayah pedesaan. Padahal, budaya ini merupakan budaya yang sangat penting dalam membantu kehidupan bermasyarakat sehari-hari. Target utama dari pengabdian masyarakat ini adalah memberdayakan masyarakat Desa Siponjot. Secara spesifik, target pada program pengabdian marsirimpa ini adalah membina tata kehidupan bermasyarakat. Sosialisasi telah dilaksanakan bersama dengan masyarakat Desa Siponjot, terkait penyampaian salah satu nilai sosial budaya yang sebenarnya telah mereka miliki (dalam konteks masyarakat Batak Toba), yaitu konsep marsirimpa, yang dapat digunakan sebagai motivasi untuk bekerjasama atau gotong royong, dan menjelaskan kekayaan alam dan lingkungan serta sumber daya manusia kreatif yang dimiliki oleh desa Siponjot. Pada tahapan ini terlihat antusiasme dan perubahan tata nilai bermasyarakat yang mendukung marsirimpa dalam kehidupan sehari-hari.
\end{abstract}

Kata kunci: Penataan Organisasi, Sumberdaya Masyarakat, Nilai Kegotongroyongan (Marsirimpa)

\section{PENDAhuluan}

\subsection{Latar Belakang Kegiatan}

Marsirimpa (gotong-royong) merupakan suatu pekekerjaan yang dilakukan secara bersama-sama denganmelibatkan beberapa orang untuk menyelesaikannya, sebelum melakukan marsirimpa (gotong-royong) mereka terlebih dahulu membuat kesepakatan untuk waktu kapan dilakukan marsirimpa tersebut, perlengkapan pangan buat seharian mereka bekerja serta ditempat siapa terlebih dahulu dilaksanakan marsirimpa tersebut. Hal ini dilakukan selain sudah sebagai tradisi bagi 
kehidupan masyarakat juga mereka merasa senasib dan sepenanggungan dalam hidup suka maupun duka, untuk hal ini tidak ada yang kaya dan miskin karena semuanya ikut marsirimpa.

Berkenaan dengan konsep kearifan lokal gotong-royong tersebut, konsep marsirimpa "kompak, serempak, bersama" sangat penting menjadi sikap bagi para peserta gotong-royong sehingga ketiga kaidah tersebut dapat diterapkan. Persyaratan awal yang harus dimiliki oleh orang yang ingin menerapkan ketiga kaidah gotong-royong tersebut adalah kekompakan (Rolitia, Achdiani, \& Eridiana, 2016). Dengan kata lain, kaidah bergotong-royong dilandasi oleh konsep "kekompakan, keserempakan, dan kebersamaan"untuk dapat mewujudkan saling memahami, menyepakati, mendukung (marsiantusan, masiaminaminan, masitungkol-tungkolan), saling membantu (marsiurupan), dan bekerja sama (rampak mangula). Contoh gotong-royong yang dimaksud dalam budaya marsirimpa adalah tim kerja seorang hasil karya penulis yang mempunyai kelompok kerja sebanyak sepuluh orang. Kelompok kerja yang sepuluh orang ini membuat suatu kesepakatan yaitu pertama, kelompok kerja tersebut akan terlebih dahulu menentukan ke lahan atau ke tempat siapa yang pertama untuk memulai pekerjaan tersebut. Kedua, makanan (sarapan, makan siang, atau snack) untuk para kelompok kerja, apakah disediakan yang mempunyai lahan pekerjaan atau dibawa masing-masing. Setelah disepakati bersama barulah para kelompok kerja ini mulai bekerja sesuai dengan kesepakatanyang telah disetujui bersama. Pekerjaan yang akan dikerjakan oleh para kelompok kerja ini ditentukan oleh orang yang bersangkutan. Kelompok kerja tersebut tidak boleh menentukan pekerjaan yang dikerjakan. Baik itu pekerjaan berat maupun pekerjaan ringan, para kelompok kerja harus siap atas pekerjaan yang sudah ditentukan oleh orang yang bersangkutan kepada para kelompok kerja (Rolitia et al., 2016)(Irfan, 2017). Demikian seterusnya bergantian mulai dari orang pertama sampai orang kesepuluh.Tetapi kebiasaan gotong-royong tersebut sudah semakin memudar.

Gotong-royong dapat menggambarkan perilaku-perilaku masyarakat desa yang bekerja untuk gotong-royong lainnya tanpa menerima upah. Lebih luas, sebagai suatu tradisi yang mengakar, meliputi aspek-aspek dominan lain dalam kehidupan sosial. Gotong-royong dalam masyarakat sebagaimana yang kita ketahui adalah suatu kegiatan yang dilakukan secara bersama-sama dan bersifat suka rela agar kegiatan yang dikerjakan dapat berjalan dengan lancar, mudah, dan ringan (Kurniawan \& Tinu, 2019). Contoh kegiatan yang dapat dilakukan secara bergotong-royong antara lain dalam hal mata pencaharian seperti menanam padi. Sikap gotong-royong itu seharusnya dimiliki oleh generasi muda atau lapisan masyarakat yang ada di Desa. Karena, dengan adanya kesadaran maka masyarakat akan melakukankegiatan dengan cara bergotong-royong. Segala sesuatu akan lebih mudah dan cepat diselesaikan jika bergotong-royong. Dengan demikian, pembangunan di daerah tersebut akan semakin lancar dan maju. Bukan itu saja,dengan adanya kesadaran setiap masyarakat dalam menerapkan perilaku gotong-royong maka hubungan persaudaraan atau silaturahim akan semakin erat.

\subsection{Permasalahan Mitra}

Masyarakat desa Siponjot secara komprehensif belum menyadari bahwa desa mereka, baik dari sisi nilai-nilai budaya lokal, potensi alam dan lingkungan, potensi dan sumber daya manusia, maupun ketersediaan waktu untuk mengembangkannya, memiliki potensi menjadi sebuah desa seni yang kreatif yang tentu berpeluang menuju desa seni (huta seni) yang mandiri, kreatif, sehat dan berbudaya (Purba \& Lumbanraja, 2019). Dalam upaya perwujudan tatanan nilai kehidupan sosial bermasyarakat yang lebih baik, diperlukan penanaman kembali budaya lokal dengan nilai kegotongroyongan, yaitu Marsirimpa. Secara aktual banyak dari masyarakat mulai kurang akrab dengan pelaksanaan kegiatan berdasarkan konsep marsirimpa tersebut.

Program pengembangan desa ini merupakan bagian dari desa binaan yang bertujuan untuk melakukan pemberdayakan masyarakat dan memberikan bimbingan serta pengarahan agar masyarakat desa Siponjot memahami potensi-potensi yang mereka miliki, mengoptimalkan kerjasama berkelompok serta membangkitkan semangat marsirimpa. Transfer ipteks dan pengembangan pengelolaan keorganisasian desa juga menjadi tujuan dari pelaksanaan program pada 
sub kegiatan ini. Diharapkan setelah kegiatan ini berakhir, masyarakat menjadi semakin kuat dan mandiri dalam mengelola desanya bersama-sama (Rolitia et al., 2016).

Sebagai bagian dari rangkaian kegiatan, penanaman nilai-nilai marsirimpa menjadi pondasi penting dalam pengelolaan dan pendorong kemandirian desa berbasis gotong royong. Upaya pengembangan dan pemaksimalan potensi desa akan tercapai dengan baik dengan memanfaatkan ipteks yang diberikan pada sub kegiatan ini. Ketahanan dan semangat desa yang kokoh akan membangun kerjasama tim yang sangat baik bagi masyarakat desa.

\subsection{Solusi yang Ditawarkan}

Dalam upaya menyelesaikan permasalahan yang dihadapi mitra, tim pengabdian telah mempersiapkan dan melaksanakan program pendekatan dengan mengadakan tatap muka dan serta diskusi secara dialogis untuk menyampaikan konsep-konsep dan penerapan Marsirimpa dalam kehidupan sehari-hari. Semangat juang untuk mencapai kepentingan bersama sekaligus meringankan beban yang terasa berat menjadi salah satu fokus dari kegiatan pengabdian ini.

\section{METODE PELAKSANAAN}

Pelaksanaan kegiatan yang dilakukan meliputi kegiatan sosialisasi dan penanaman nilai-nilai biudaya kepada masyarakat. Sosialisasi kegiatan pengabdian ini dimulai dengan memberikan penjelasan secara rinci tentang potensi desa Siponjot yang memiliki kekayaan alam dan lingkungan, memiliki nilai-nilai sosial dan budaya (marsirimpa) yang dapat dimanfaatkan untuk mendukung peningkatan ekonomi dan kesejahteraan masyarakat desa. Dari kegiatan ini diharapkan masyarakat desa Siponjot dapat mengejawantahkan pemahaman marsirimpa ini dalam bentuk kerja gotongroyong baik secara kelompok atau komunitas, maupun secara huta ke huta.Target atau sasaran yang ingin dicapai dalam hal ini adalah terbentuknya kelompok-kelompok kerja yang mengutamakan kerjasama atau sama-sama bekerja untuk tujuan kemajuan dan keberhasilan bersama masyarakat desa.Nilai budaya marsirimpa dalam kegiatan ini menjadi sentral dan acuan untuk kegiatan-kegiatan yang dilakukan. Secara lebih spesifik pengabdian ini mengadakan tatap muka dan berdiskusi secara dialogis dengan masyarakat desa Siponjot, dimana akan dijelaskan salah satu nilai sosial budaya yang mereka miliki (dalam konteks masyarakat Batak Toba), yaitu konsep marsirimpa, yang dapat digunakan sebagai motivasi untuk bekerjasama atau gotongroyong, dan menjelaskan kekayaan alam dan lingkungan serta sumber daya manusia kreatif yang dimiliki oleh Desa Siponjot.

\section{HASIL DAN PEMBAHASAN}

Rangkaian kegiatan pengabdian Desa Binaan di Desa Siponjot dibuka dengan memberikan ipteks dan sosialisasi terkait marsirimpa, dengan mengingatkan dan memperkokoh kembali budaya Suku Batak untuk saling bergotong-royong, tolong-menolong untuk membantu sesama warga. Marsirimpa juga akan memperkokoh keorganisasian masyarakat desa dimana semua saling bersatu untuk mencapai tujuan bersama. Keberhasilan pada program ini akan sangat membantu pencapaian tujuan besar dari kegiatan pengembangan desa pada program Desa Binaan, sekaligus memperlancar pencapaian tujuan dari rangkaian kegiatan (sub program) lainnya dari program Desa Binaan ini. 
Jhonson Pardosi et.al. Marsirimpa as Core Cultural Value to Improve Social Value

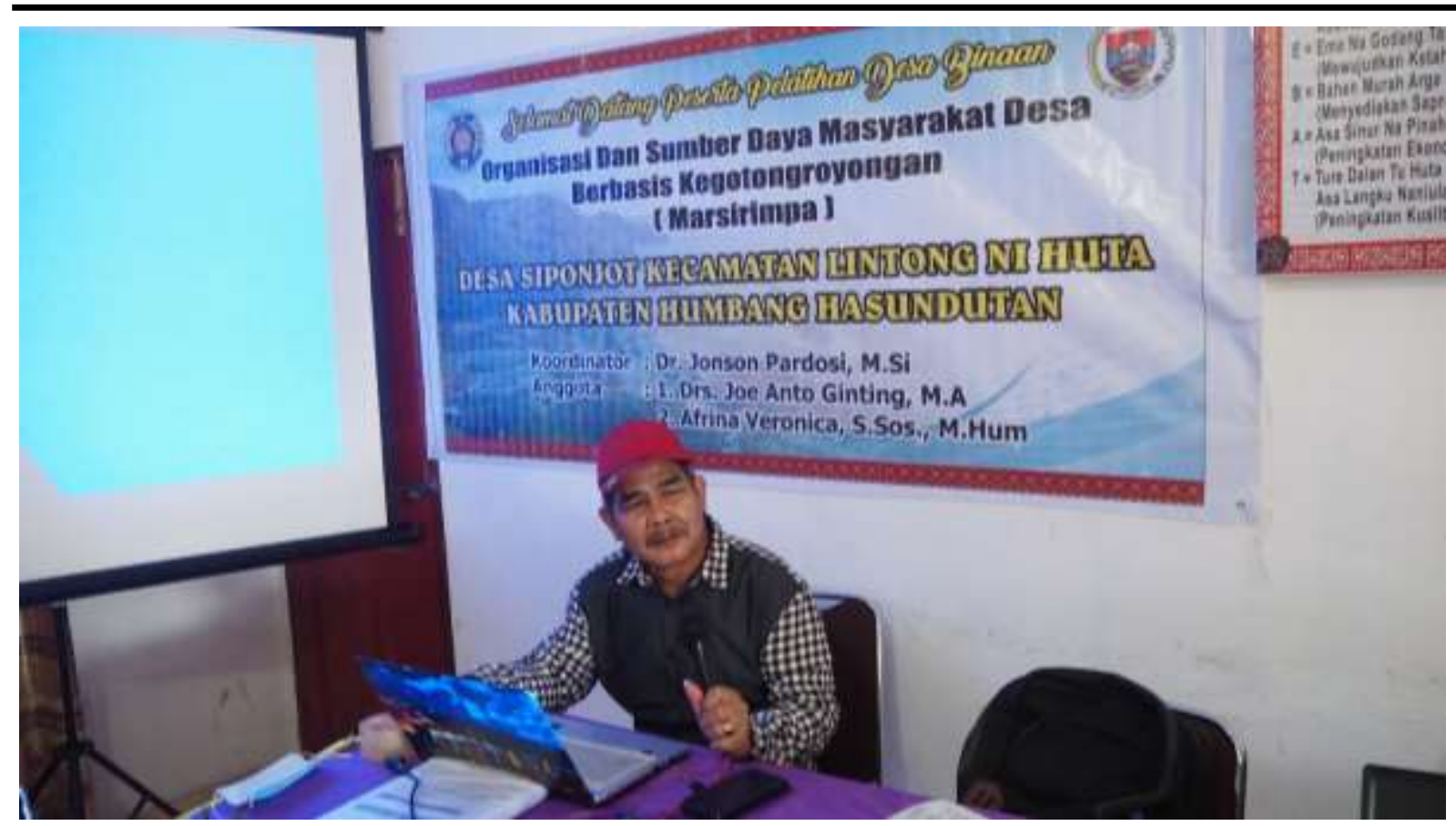

Gambar 3.1. Pemberian Sosialisasi Ipteks Keogranisasian dan Marsirimpa

Pemberian ipteks terkait keogranisasian dan marsirimpa dibawakan oleh Drs. Joe Anto Ginging, M.A., selaku anggota dari tim pada sub program pertama. Kegiatan ini dilaksanakan di Kantor Kepala Desa Siponjot pada Sabtu, 01 Agustus 2020. Warga desa turut menghadiri rangkaian kegiatan pengabdian dengan undangan langsung dari kepala desa. Kegiatan ini juga melaksanakan komunikasi dua arah antara tim dengan warga desa terkait keuntungan dan kelemahan dari marsirimpa dari sudut pandang warga dan akademisi.

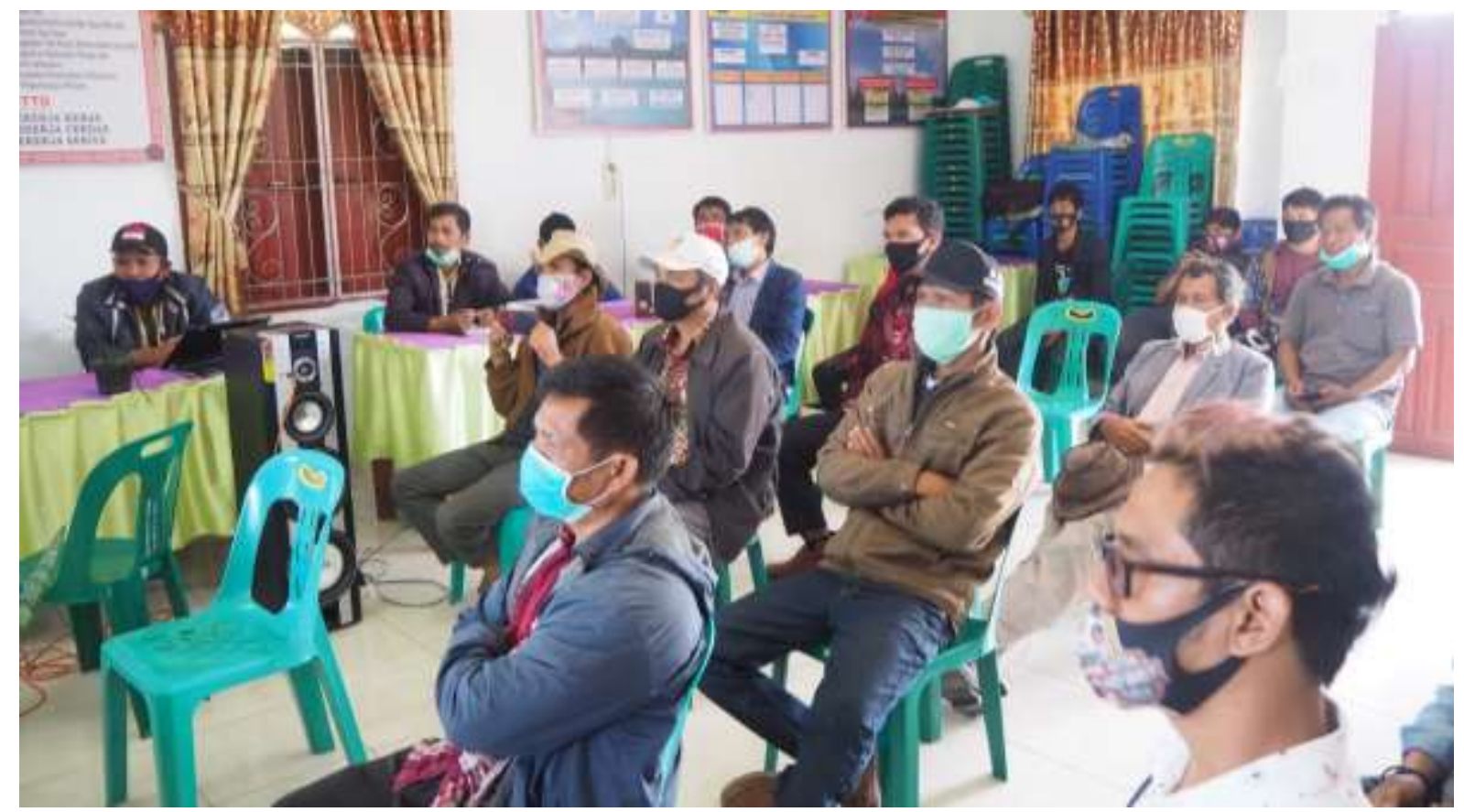

Gambar 3.2. Antusiasme Warga pada Sosialisasi Marsirimpa

Marsirimpa, bagi masyarakat Desa Siponjot merupakan budaya yang sebenarnya secara turun temurun telah dilaksanakan pada kehidupan sehari-hari. Hasil diskusi dengan masyarakat 
menunjukkan bahwa individualisme yang mulai tumbuh di kalangan masyarakat mulai memudarkan pelaksanaan budaya tersebut di kehidupan sehari-hari (Sonnentag \& Frese, 2005). Banyak dari masyarakat desa memilih personal gain atas usaha individu yang lebih menjanjikan daripada bergotong-royong untuk saling membantu kepentingan bersama. Salah satu kendalanya adalah rasa khawatir akan ketidakadilan yang mungkin muncul dari pelaksanaan marsirimpa, dimana rasa saling tolong menolong tersebut tidak berbalik ketika warga lain membutuhkannya. Dibalik kekhawatiran tersebut, masyarakat masih melihat bahwa marsirimpa merupakan hal yang sangat baik untuk saling membantu, khususnya untuk mencapai manfaat bagi khalayak ramai. Masyarakat desa kembali membangun komitmen untuk saling tolong menolong, bahu membahu untuk kepentingan bersama.

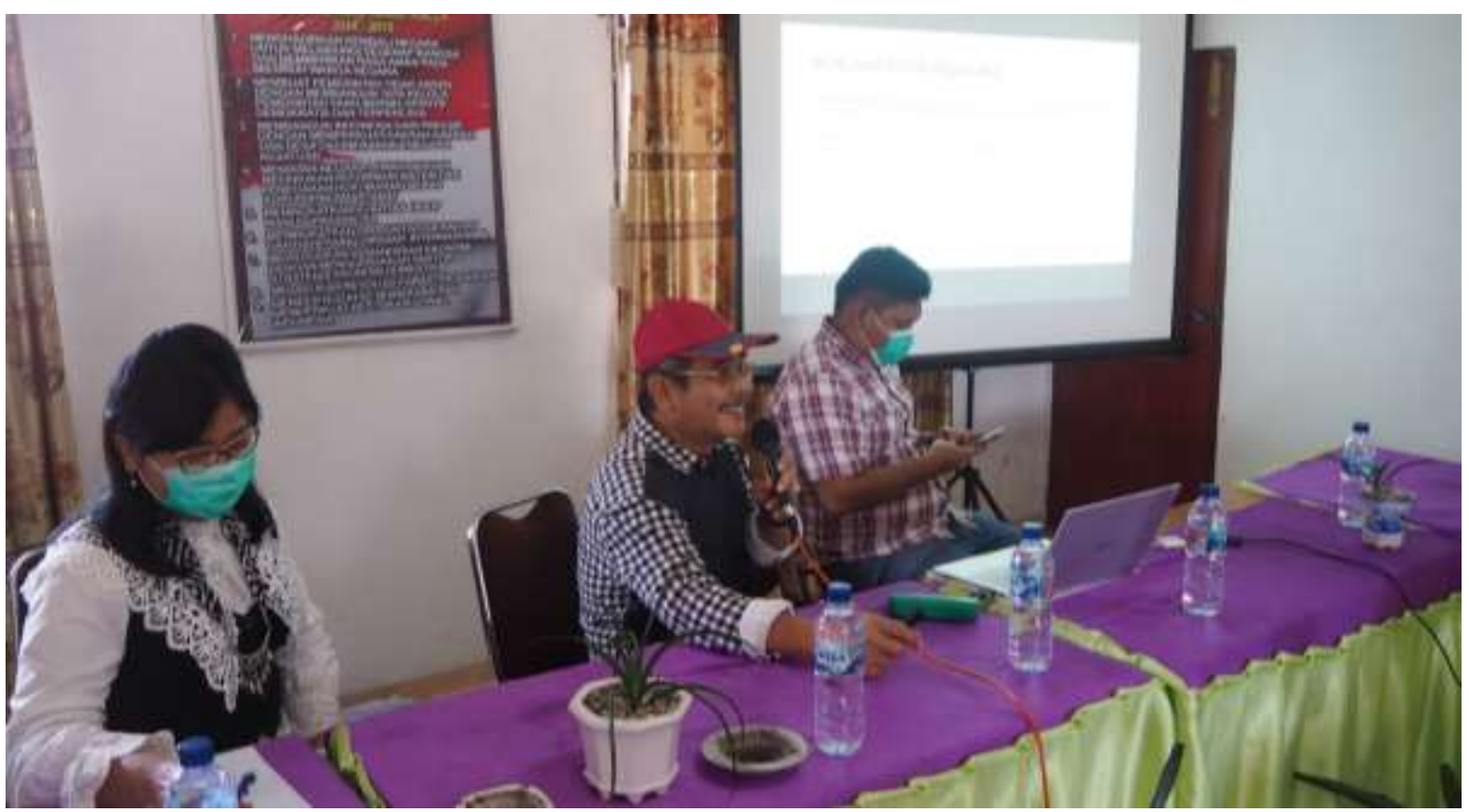

Gambar 3.3. Focus Group Discussion dengan Warga Siponjot

Pelaksanaan focus group discussion dilakukan oleh tim bersama dengan warga setempat. Perlu kembali disampaikan bahwa seluruh rangkaian kegiatan di Desa Siponjot tetap memperhatikan protokol kesehatan dengan menjaga jarak antara warga peserta sosialisasi dan diskusi kelompok dengan tetap memakai masker (Satuan Tugas Penagnanan Covid-19, 2020). Diskusi yang diawali dengan perbedaan pendapat berlangsung dengan tertib dan memberikan masukan yang berharga baik kepada tim maupun kepada warga setempat. 


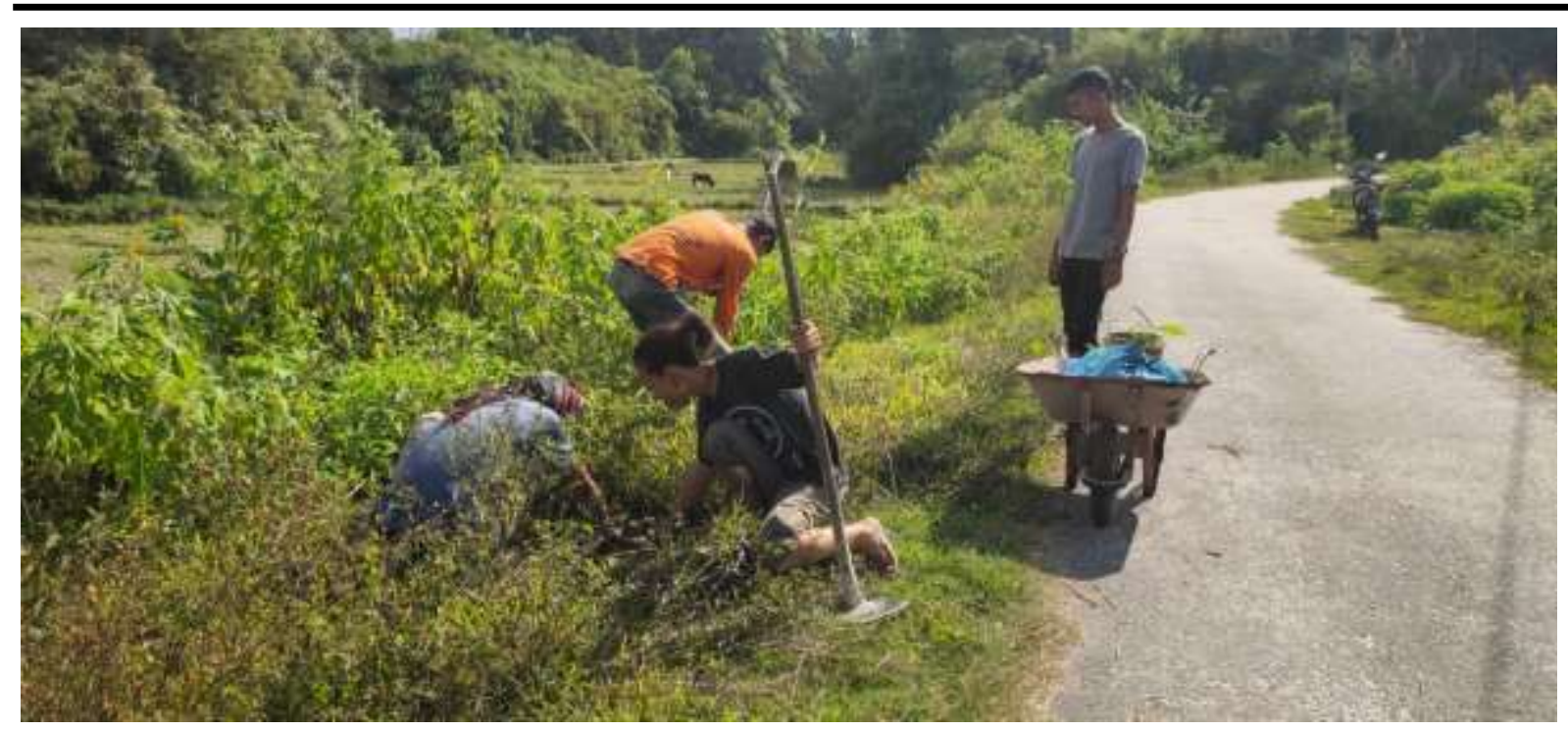

Gambar 3.4. Pelaksanaan Marsirimpa pada Penanaman Benih dan Pembersihan Lahan

Warga secara aktif melaksanakan gotong-royong, bukti penerapan dari ipteks marsirimpa yang kembali diterapkan oleh warga. Aktivitas warga dalam membudidayakan kembali hutan desa dilaksanakan secara gotong royong. Warga menyisihkan waktunya selain bekerja untuk memenuhi keperluan sehari-hari, dengan bersama-sama melaksanakan tanggung jawab sekaligus tugas bersama untuk membangun dan memajukan Desa Siponjot.

Tim pengabdian kembali melakukan kunjungan ke Desa Siponjot sebagai rangkaian kegiatan persiapan pelaksanaan pagelaran seni perdana yang akan dilaksanakan pada 28 November 2020 mendatang. Pada kunjungan ini tim sangat berharap makna kegotongroyongan (marisirimpa) sudah semakin tercermin dalam masyarakat desa. Penyelenggaraan pagelaran seni ini memerlukan kontribusi dan kerjasama dari seluruh bagian masyarakat desa sebagai pelaksana, bukan hanya anggota sanggar seni saja.

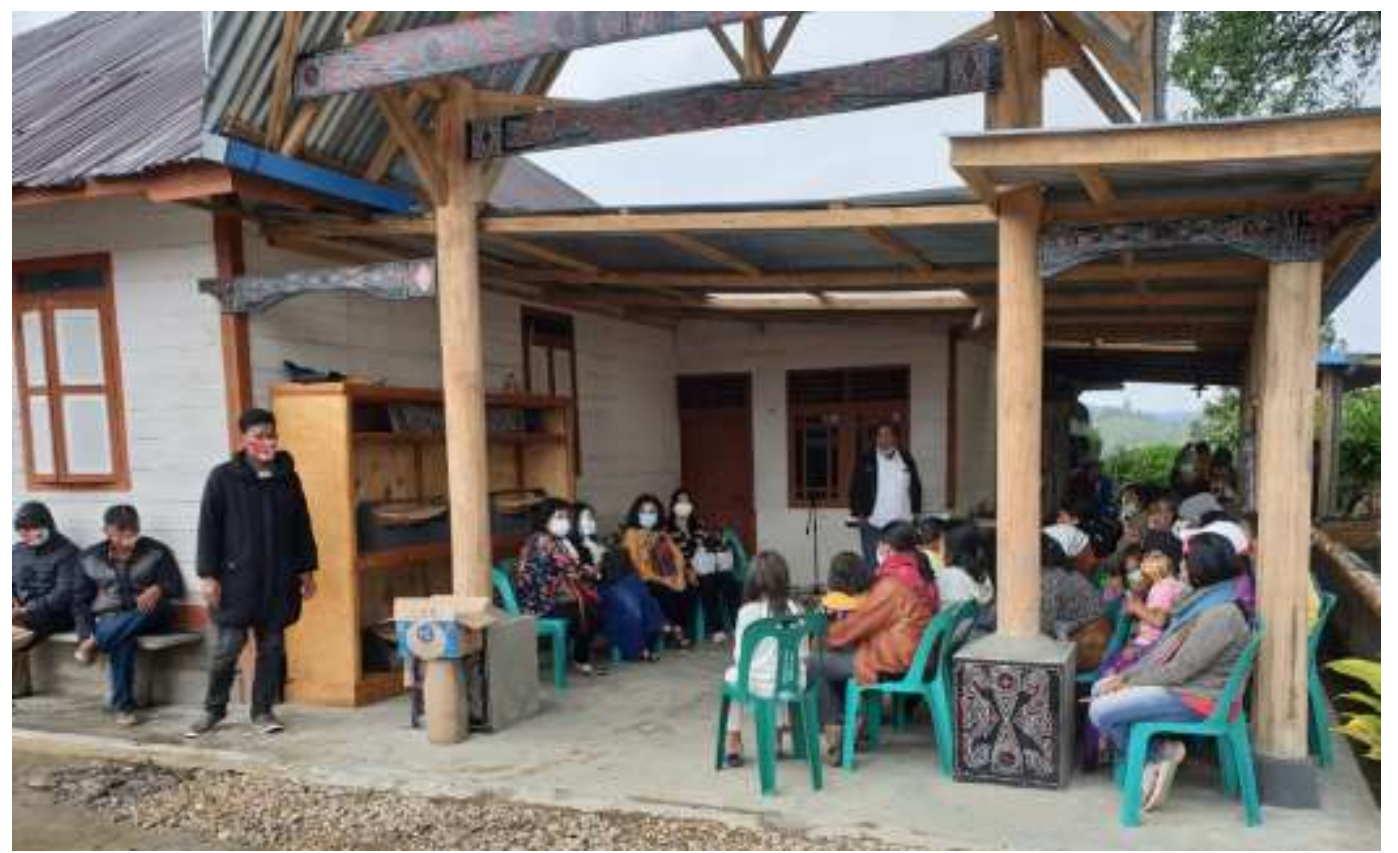

Gambar 3.5. Masyarakat Desa bersama Sanggar Seni Merencanakan Pelaksanaan Pagelaran Seni 
Pada undangan rapat pelaksanaan pagelaran seni di Desa Siponjot, kami memperoleh respon positif dan antusiasme yang sangat tinggi dari pihak masyarakat desa. Masyarakat desa sudah menganggap kegiatan pagelaran seni ini sebagai kegiatan bersama yang ditujukan untuk memajukan Desa Siponjot. Marsirimpa yang sangat kuat tercermin dalam aktivitas ini dimana sebagian besar warga desa mau meluangkan waktunya untuk menyukseskan kegiatan bersama antara tim, sanggar seni, serta masyarakat desa yang saling berkoordinasi dalam melaksanakan pagelaran seni Desa Siponjot sebagai eksistensi Desa Siponjot sebagai desa seni yang mendukung pengembangan kawasan wisata Danau Toba di masa yang akan datang.

\section{KESIMPULAN}

Kegiatan pengabdian pada masyarakat yang telah dilaksanakan membantu masyarakat dalam meningkatkan tatanan nilai bermasyarakat. Budaya marsirimpa, dalam konsepnya masih melekat pada warga desa, namun pada implementasinya banyak yang mulai meninggalkan budaya tersebut dan lebih fokus pada aktivitas individu yang dirasakan lebih menjanjikan bagi masyarakat. Pemberian motivasi dan dukungan sebagai fasilitator atau penggerak pada aktivitas masyarakat desa sangat membantu pada implementasi marsirimpa dalam kehidupan sehari-hari dari masyarakat desa. Penerapan budaya marsirimpa dalam kehidupan sehari-hari sangat membantu pencapaian tujuan bersama dengan efektif dan efisien. Adaptabilitas marsirimpa merupakan kebiasaan yang harus dipertahankan oleh warga. Oleh karena itu, kesuksesan pembangkitan kembali budaya marsirimpa di kehidupan sehari-hari sangat ditentukan oleh individu berbagai aktivitas masyarakat desa.

\section{UCAPAN TERIMAKASIH}

Terima kasih kepada Universitas Sumatera Utara khususnya Lembaga Pengabdian Masyarakat USU yang telah mendanai kegiatan pengabdian ini di bawah program Desa Binaan USU Tahun 2020. Terima kasih pula kepada seluruh warga Desa Siponjot serta dukungan aparatur pemerintah dalam mendukung pelaksanaan program ini.

\section{DAFTAR PUSTAKA}

Irfan, M. (2017). Metamorfosis Gotong Royong Dalam Pandangan Konstruksi Sosial. Prosiding Penelitian Dan Pengabdian Kepada Masyarakat, 4(1), 1. https://doi.org/10.24198/jppm.v4i1.14204

Kurniawan, V., \& Tinu, A. (2019). Pelestarian Nilai Gotong-Royong Melalui Kelompok Seni Kuda Lumping. Civic Hukum, 4(2), 174-182.

Purba, M., \& Lumbanraja, P. (2019). Empowerment of Silaban margu arts sanggar as crafts of Batak Toba music tradition instruments in Huta Sitangkuban village Siponjot Kecamatan Lintong Ni Huta district Humbang Hasundutan Department of Ethnomusicology , Cultural Sciences , Universitas Sumatr. ABDIMAS TALENTA: Jurnal Pengabdian Kepada Masyarakat, 4(2), 647655.

Rolitia, M., Achdiani, Y., \& Eridiana, W. (2016). Nilai Gotong Royong Untuk Memperkuat Solidaritas Dalam Kehidupan Masyarakat Kampung Naga. Sosietas, 6(1). https://doi.org/10.17509/sosietas.v6i1.2871

Satuan Tugas Penagnanan Covid-19. (2020). Pedoman perubahan perilaku. Jakarta: Satuan Tugas Penanganan Covid-19.

Sonnentag, S., \& Frese, M. (2005). Performance Concepts and Performance Theory. Psychological Management of Individual Performance, (January), 1-25. https://doi.org/10.1002/0470013419.ch1 